\title{
Training the endoscopy trainer: From general principles to specific concepts
}

\author{
Sylvain Coderre MD FRCPC ${ }^{1}$, John Anderson BSC FRCP(Edin) MD², \\ Alaa Rostom MD FRCPC ${ }^{1}$, Kevin McLaughlin MD MRCP ${ }^{3}$
}

\begin{abstract}
S Coderre, J Anderson, A Rostom, K McLaughlin. Training the endoscopy trainer: From general principles to specific concepts. Can J Gastroenterol 2010;24(12):700-704.

Endoscopy instruction has progressed a great deal in recent years, evolving from the age-old dictum of 'see one, do one' to the current skillful application of sound educational principles. Some of these educational principles are generic and applicable to the teaching of any content at all levels, while others are quite specific to technical skills training. The present review summarizes these important principles under the following headings: creating a learner-centred curriculum; delivering an achievable learning task; and moving from theory to practice. The present article challenges national gastroenterology organizations to embrace these concepts in structured, outcome-based educational programs.
\end{abstract}

Key Words: Cognitive load theory; Curriculum; Deliberate practice; Endoscopy training; Skills acquisition

\section{CREATING A LEARNER-CENTRED CURRICULUM}

The following represent the three fundamental pillars of all educational interventions: curriculum (objectives); learning experiences; and evaluation (including feedback) (1). Whether designing an entire curriculum, a course or a single educational encounter, establishing these pillars and, most importantly, congruence between these pillars, is fundamental to a successful intervention (2). In the context of an endoscopy teaching event, setting objectives can be accomplished succinctly before the training session using such tools as SMART- an acronym representing the features attributable to quality objectives: Specific, Measurable, Achievable, Relevant and Timely (3).

Two of these characteristics - relevance and achievability deserve special attention because they require important additional steps for objective setting. For objectives to be achievable, the trainer must first clearly establish the trainee's educational level and experience. This information is important for teaching both knowledge and skills because the rate-limiting step to new information storage is the amount of previous knowledge present in an individual's memory (4). Second, relevance of educational objectives to the learner requires a discussion of trainer and trainee objectives and expectations, a process known as aligning agendas (5). Learning events that are purely driven by the trainer can remove meaning to the learner, which results in two educational pitfalls. The meaning of educational material is essential for effective memory organization (4) in addition to comprising a fundamental component of intrinsic learner motivation (6).

\section{La formation des formateurs en endoscopie : Des principes généraux aux concepts spécifiques}

\begin{abstract}
L'enseignement de l'endoscopie a beaucoup évolué ces dernières années, passant du vieux dicton « observe et reproduit » à l'application adroite actuelle de solides principes pédagogiques. Certains de ces principes pédagogiques sont génériques et applicables à tout type d'enseignement quel que soit le niveau, tandis que d'autres sont propres à l'enseignement de compétences techniques. La présente analyse contient le résumé de ces principes importants, sous les rubriques suivantes : créer un programme axé sur l'apprenant, donner une tâche d'apprentissage réalisable et passer de la théorie à la pratique. On y exhorte les organisations nationales de gastroentérologie à adopter des principes dans des programmes de formation structurés axés sur les résultats.
\end{abstract}

The process of establishing learner level, setting objectives and aligning agendas leads to the learning experience, which will be discussed in detail below. Evaluation effectively closes this educational loop and, in the case of a single educational event such as teaching during an endoscopy list, evaluation is usually noncertifying in the form of performance-enhancing feedback. Providing feedback is an essential component of learning activities and aims to encourage learner self-reflection, self-awareness, and planning for future learning and practice (7). There are a number of characteristics that comprise good feedback; however, overall specific, immediate on directly observed, improvable behaviour is the best method to enhance future performance.

There are several models of feedback delivery that can be followed. One popular model is the Pendleton approach (7), which relies on the trainee self-assessing the positives from the training, confirmed and, if necessary, added to by the preceptor. The trainee is then asked to reflect and highlight any potential areas for improvement. This, again, is followed by the preceptor's impression, and a discussion regarding future behaviour and improvement strategies. Providing feedback is a cornerstone of any teaching event including skills training (8). However, common to all training events and interaction, the potential exists for feedback to be harmful. In a novice learner, limited feedback appears to be superior to intense feedback (9). Moreover, intense concurrent feedback while a trainee is performing a task increases short-term acquisition, but can negatively impact long-term skills acquisition (if withdrawn) and lead to maladaptive short-term behaviour corrections $(10,11)$.

${ }^{1}$ Department of Medicine, Division of Gastroenterology, University of Calgary, Calgary, Alberta; ${ }^{2}$ Department of Gastroenterology,

Gloucestershire Hospitals National Health Service Foundation Trust Hospital, United Kingdom; ${ }^{3}$ Office of Undergraduate Medical Education,

University of Calgary, Calgary, Alberta

Correpsondence: Dr Sylvain Coderre, Department of Medicine, Division of Gastroenterology, University of Calgary, 2500 University Drive

Northwest, Calgary, Alberta T1Y 6J4. Telephone 403-943-5708, fax 403-943-4471, e-mail coderre@ucalgary.ca or scoderre@shaw.ca

Received for publication June 21, 2010. Accepted June 23, 2010 


\section{DELIVERING AN ACHIEVABLE LEARNING TASK}

With these building blocks in place, it is now time to deliver a high-quality teaching session focused on attaining realistic learner goals. The question remains, how do we decide on achievable tasks? To best proceed as an endoscopy trainer, two important educational concepts must be understood: the stages of skill acquisition and cognitive load theory (CLT). The following discusses these two important concepts and educational strategies that adhere to these principles and maximize endoscopic skills education.

The road to acquiring competency and, at times, excellence in the performance of any skill, requires a combination of innate biological capacities, dedicated teachers and many hours of training. The process of skill acquisition has been described as undergoing a sequential process involving three major phases (12). The first phase, also known as the novice phase, involves intense concentration to fully understand the activity and avoid making mistakes. The second phase is an evolution to a more fluid, less cognitively arduous step in which trainees start to perform at an acceptable level with fewer major mistakes. The final phase involves a process of automation, in which the skill is precisely and smoothly performed with little or no conscious cognitive involvement. These phases have been demonstrated in several skill areas including recently in the surgical arena (13).

Different terminology has been used to describe a similar sequence of events. The terms unconscious and conscious incompetence have been used to describe the early training stage, evolving to conscious competence (similar to Ericsson's second phase [12]) and, finally, unconscious competence for the more automated phase of skill acquisition (14). Other terms for this three-step process have included the cognitive, associative and autonomous phases (15). Starkes et al (15) proposed a perceptual-motor skill acquisition and retention model that is also consistent with the general principles of the skills acquisition previously outlined. This model captures the transition of both perceptual-cognitive and perceptual-motor behaviour throughout skills acquisition. The cognitive components of this model have been significantly influenced by the description of medical expertise cognitive evolution reported by Schmidt et al (16).

In the Starkes et al (15) model, the evolution from novice to expert proceeds in four major phases. Phase I, termed the acquisition phase, is a step characterized by the acquisition of declarative knowledge, procedural rules ('if then do' statements) and an increasing amount of procedural skills. At this stage, the procedural skills are constrained because of motor and cognitive deficiencies (eg, limited ability to strategize). Phase II of the model, termed the elaboration/condensation phase, describes an evolving cognitive process in which content can be condensed using techniques such as 'chunking' (17), which translates to increased linking, diversity and efficiency of movements. Phase III (routine expertise) and phase IV (transcendent expertise) of the model discuss the expertise level, in which experience and practice allow for the development of scripts. Scripts or, in medical terms, illness scripts (16), are a repertoire of problems or situations common to a certain domain. Scripts allow for rapid problem resolution by the recognition of new problems or situations that are similar or identical to former problems or situations that were previously solved. This type of reasoning relies on heightened attention to contextual factors and less reliance on sets of rules - a process also termed nonanalytical reasoning or pattern recognition (18). From a motor perspective, expertise allows for the development of longer movement scripts, increased efficiency of motion and a greater range of movement options. Phase IV differs from phase III by describing the supreme level of acquisition for a certain discipline and, thus, represents the pinnacle of efficiency, effort optimization, innovation and success.

There is no doubt that experts and novices differ in both the cognitive and motor perspectives. Experts perform skills faster than novices, perform their tasks with fewer errors, and have superior short- and long-term memory, knowledge structures and problem representations (19). Experts have heightened attention abilities, with superior selective attention to important and relevant cues, as well as an increased ability to attend to several stimuli simultaneously (20). Dual task performance increases with expertise, whereas novices can experience great difficulty with dual tasking (5). The issue of how expertise is achieved has received much attention, with the relative weighting of innate abilities versus practice in expertise attainment remaining a topic of controversy (21).

The traditional view of expertise skill development described a process in which experience alone was the driving force in the evolution from novice to expert. The level achievable by an expert was relatively fixed and set by the individual's genetically determined limits. Ericsson (12) proposed a different view of skill acquisition, referred to as deliberate practice. In this model, consistent, gradual improvements of performance can occur, even once a so-called 'expert' level has been attained. For this to occur, three training conditions must be met. First, trainees are instructed to improve a clearly defined task that is set at an appropriate level. Second, the trainees are given immediate and precise feedback on their performance. Finally, trainees are given many opportunities to perform and repeat the tasks in training, with the caveat that training sessions are limited to $1 \mathrm{~h}$, although others (19) have proposed a 2 h to 4 h range of training time as potentially acceptable. Ericsson (12) viewed practice as the dominant factor in the steady, progressive acquisition of expertise over time. In general, for complex tasks, acquisition of the entire skill tends to be progressive and gradual. The length of time required to achieve expertise varies from being relatively short $(50 \mathrm{~h} \mathrm{[12])} \mathrm{for} \mathrm{everyday} \mathrm{skills} \mathrm{such} \mathrm{as} \mathrm{driving} \mathrm{a}$ car, to 10 years for certain skills such as achieving an international performance level in chess (22).

It is important to recognize the training stage of an endoscopy trainee for many reasons. It should also be recognized that all endoscopists continue to learn and may find themselves as trainees again with regard to a specific technique or procedure, even as an independent practitioner. As discussed in the section on objectives, the rate-limiting step for new information to be stored into learner memory is the amount of previous knowledge. Learners at different levels may respond differently to various techniques. Some techniques may be dysfunctional if introduced too early in the training, while others can be useful in novices, but become less effective or even counterproductive in more advanced learners $(5,19)$. One important reason for this variation relates to the critical concept of CLT. 
The theories of skills acquisition identify the mechanisms by which experts acquire skills and superior achievements without the aim of translating these mechanisms into general instruction for complex skills in educational settings. In contrast, CLT has focused mainly on developing effective and efficient instructional strategies to support initial skill acquisition in educational settings. First described by Sweller (23), CLT fundamentally holds that "instructional design should explicitly consider the human cognitive architecture and its limitations in order to be effective" (24). CLT proposes that cognitive architecture is comprised of a limited general purpose working memory (seven 'chunks' of information for basic information storage, and two to three for processing information) and a long-term memory that has unlimited capacity.

It is critical that all educators consider cognitive loading in the design of educational interventions. Certain sources of cognitive loading, termed germane or effective loads, are useful in domain-specific knowledge/skill acquisition by reducing working memory load (19). However, some educational interventions, by virtue of increasing what is termed extraneous or ineffective cognitive load, can have a negative impact on the training process.

In novices, the introduction of several competing stimuli, especially if poorly designed, can be a source of extraneous cognitive load through a process of split attention (25). This is particularly true for complex skills such as colonoscopy, as opposed to other relatively simple practical tasks (26).

\section{MOVING FROM THEORY TO PRACTICE}

The challenge now is to apply the skills acquisition and CLTs to the daily endoscopic 'deliberate practice' of our trainees. The potential for cognitive overload during endoscopy training is quite significant. Consider a novice endoscopist who is just beginning to learn a complex skill such as colonoscopy. By virtue of being at Ericsson's first stage of training, intrinsic cognitive load is high due to intense concentration and maximal attentional load (27). Extrinsic cognitive load is also high because of the proprioceptive stimuli received from the colonoscope, verbal stimuli from the patient and nursing staff, and visual input from the luminal view of the colon. In addition, the educational component of the task adds further information such as verbal direction from the trainer and, in some centres, additive visual input from the endoscope positioning guide (eg, Olympus Scope Guide, Olympus, Japan) (see pages 727-732 in this issue of the Journal).

As trainers of a novice endoscopist, what teaching techniques can we use to minimize the counterproductive extraneous cognitive load and maximize the effective germane cognitive load? At this stage, the learner's agenda and attention are completely focused on skills acquisition; thus, verbal instruction relating to knowledge acquisition should be eliminated during the procedure and presented after the procedure is completed.

Verbal instruction of colonoscope position and movement can be simplified by using a set of 12 direct, simple terms such as tip up, tip down, tip left, tip right, clockwise torque, anticlockwise torque, insufflate, aspirate, advance/push forward, withdraw/pull back, stop and slowly (5). Of all these terms, 'stop' is the most important at this stage, both for patient safety and in instances for which more elaborate verbal instruction are required $-\mathrm{a}$ ground rule best established when setting objectives. Because any trainee may have several different trainers, keeping didactic instructions clear, concise and consistent has obvious advantages. More liberal verbal instruction and discussion can be presented to a more advanced trainee whose progression through the initial training stages has led to decreased cognitive effort and more automated movements.

One useful strategy to reduce cognitive load can be borrowed from the literature pertaining to knowledge acquisition. Information 'chunking', such as seen in diagnostic classification schemes (28) (eg, prerenal, renal and postrenal causes of renal failure), truncates a long list of diagnostic possibilities into smaller, more manageable bundles that, once acquired, can be viewed as one piece of information in working memory, thus reducing working memory load. The skills acquisition equivalent of this process is the deconstruction of endoscopy skills into smaller units, which has been shown to be useful in many skills training areas (29). For example, the skill of colonoscopy can be broken down into distinct skills such as colonoscope set-up, torque steering and loop resolution, followed by discrete smaller objectives such as navigating the rectum, sigmoid colon, splenic/hepatic flexures, ascending colon and, finally, intubation of the terminal ileum. Reducing the emphasis on the goal of cecal intubation, which is all too often the primary concern of even novice trainees, can result in a set of more manageable and realistic skill objectives that help increase training success and reduce training stress. For the novice learner at the 'conscious' stage of training, setting a goal of transverse colon intubation seems appropriate because it allows for the deconstruction of key steps in colonoscopy such as traversing the sigmoid/descending colon junction and loop resolution/position changes to attain and navigate the splenic flexure. Table 1 summarizes the challenges associated with each learner stage and proposes a solution, practice task and evaluation plan for each stage.

It is important to note that many of these deconstructed skills can be practiced outside of the patient, and certainly can be applied to simulation training. Training events occurring outside of the patient can take many different forms and offer distinct benefits to skills education. One simple training strategy that does not directly involve the patient is mental and physical rehearsal before the endoscopies, which has been shown in the surgical literature to be beneficial (30), likely due to improving memory retrieval by way of cognitive elaboration (16). Simulation has been shown to be useful in endoscopy (31) and surgery (32) including emerging data regarding transferability of simulated skills to the real patient (33). Simple observation of a demonstration by an expert (34), especially when the trainee verbalizes what he/she is seeing $(35,36)$, can also be a useful technique. All of these nonpatient methods have the advantages of safety and allowing for errors, which serve to solidify the encoding and retrieval information trail in memory (37).

Quality and safety of patient endoscopy requires high-quality, safe endoscopic training. The United Kingdom has become a world leader in this area by introducing several courses such as 'Train the Trainers', 'Colonoscopy Basic Skills', 'Advanced Polypectomy Skills', as well as a number of measures of endoscopy quality such as the directly observed procedural skills assessment and the global rating scale. It is imperative that 
TABLE 1

Framework for a learner-centred endoscopy skills training curriculum

\begin{tabular}{|c|c|c|c|c|}
\hline Learner stage & Challenge & Possible solution & Practice tasks & Evaluation \\
\hline Conscious & High intrinsic load & Task deconstruction & $\begin{array}{l}\text { Transverse colon intubation, loop } \\
\text { resolution }\end{array}$ & $\begin{array}{l}\text { Patient comfort, elapsed time, cognitive load } \\
\text { measure }\end{array}$ \\
\hline Associative & Need to feel challenged & Increase complexity of tasks & Cecal intubation, polypectomy & Cecal intubation rates, patient comfort \\
\hline Autonomous & $\begin{array}{l}\text { Skills not amenable to } \\
\text { conscious reflection }\end{array}$ & Enforce conscious reflection & $\begin{array}{l}\text { Teaching, scope position } \\
\text { guide }\end{array}$ & $\begin{array}{l}\text { Withdrawal time, complication rates, teaching } \\
\text { evaluation }\end{array}$ \\
\hline
\end{tabular}

Canada follows this lead with endoscopy 'Train the Trainers' courses designed not only to follow the basic principles outlined in the present article, but which also follow discrete outcome measures as to the success of these courses. Educational interventions must not be assumed to be favourable; therefore, data needs to be collected in the following areas to ensure that these courses are, in fact, not harming participants:

- Pre- and postparticipant qualitative assessment of their own teaching;

- Pre- and postquantitative assessment of participant teaching from trainees;

- Reduced trainee workload (as measured by the National Aeronautics and Space Administration task load index score [38]) when trained by course participants;

\section{REFERENCES}

1. Suter E, Mandin H, Small P. The sciences in the education of physicians. Basic Sci Educ 1998;8:7-9.

2. Coderre S, Woloschuk W, McLaughlin K. Twelve tips for blueprinting. Med Teach 2009;31:322-4.

3. National primary and care trust development programme. Ten steps to SMART objectives. <http://www.natpact.nhs.uk> (Accessed on August 3, 2004).

4. Regehr G, Norman G. Issues in cognitive psychology: Implications for professional education. Acad Med 1996;71:988-1001.

5. Anderson J. Teaching colonoscopy. In: Waye JD, Rex DK, Williams CB, eds. Colonoscopy: Principles and Practice, 2nd edn. New York: Wiley-Blackwell, 2009:141-53.

6. Schmidt H. Foundations of problem-based learning: Some explanatory notes. Med Educ 1993;27:422-32.

7. Vickery A, Lake F. Teaching on the run tips 10: Giving feedback. Med J Aust 2005;183:267-8

8. Porte MC, Xeroulis G, Reznick R, Dubrowski A. Verbal feedback from an expert is more effective than self-accessed feedback about motion efficiency in learning new surgical skills. Am J Surg 2007;193:105-10

9. Stefanidis D, Korndorffer JR, Heniford T, Scott DJ. Limited feedback and video tutorials optimise learning and resource utilisation during laparascopic simulator training. Surgery 2007;142:202-6.

10. Schmidt RA, Wulf G. Continuous concurrent feedback degrades skill learning: Implications for training and simulation. Hum Factors 1997;39:509-25.

11. Wulf $G$, Shea C. Understanding the role of augmented feedback: The good, the bad and the ugly. In: Williams AM, Hodges NJ, eds. Skill Acquisition in Sport: Research, Theory and Practice. London: Routledge, 2004:121-44.

12. Ericsson A. Deliberate practice and the acquisition and maintenance of expert performance in medicine and related domains. Acad Med 2004 (Suppl);79:570-81.

13. Zheng B, Cassera MA, Martinec DV, Spaun GO, Swanstrom LL. Measuring mental workload during the performance of advanced laparoscopic tasks. Surg Endosc 2010;24:45-50.

14. Wikipedia. Four stages of competence. <http://en.wikipedia.org/ wiki/Four_stages_of_competence> (Accessed on May 13, 2010).

15. Starkes J, Cullen J, Macmahon C. A life-span model of the acquisition and retention of expert perceptual-motor performance.
- Improved endoscopy quality measures in trainees such as complication rates, patient comfort and realistic distance measures (transverse colon for first year, cecum for second year) achieved; and

- If the best way to learn is by teaching, then improved teaching should lead to improved consultant endoscopic quality

Designing educational interventions that follow these principles is significantly challenging, and finding measurable positive outcomes of these interventions is even more challenging. However, it remains essential for widespread acceptance and engagement into a process that will, hopefully, lead endoscopy in Canada toward the ultimate goal of superior quality and improved patient care.

In: Williams AM, Hodges NJ, eds. Skill Acquisition in Sport: Research, Theory and Practice. London: Routledge, 2004:259-81.

16. Schmidt H, Norman G, Boshuizen H. A cognitive perspective on medical expertise: Theory and implications. Acad Med 1990;65:611-21.

17. Chase W, Simon H. Perception in chess. Cognit Psychol 1973;1:55-81.

18. Norman G, Brooks L. The non-analytical basis of clinical reasoning. Adv Health Sci Educ Theory Pract 1997;2:173-84.

19. van Gog T, Ericcson A, Rikers R, Paas F. Instructional design for advanced learners: Establishing connections between the theoretical frameworks of cognitive load and deliberate practice.

Education ResearchTech Dev 2005;53:73-8.

20. Janelle C, Duley A, Coombes S. Psychophysiological and related indices of attention during motor skill acquisition. In: Williams AM, Hodges NJ, eds. Skill Acquisition in Sport: Research, Theory and Practice. London: Routledge, 2004:282-308.

21. Ward P, Hodges N, Williams AM, Starkes J. Deliberate practice and expert performance: Defining the path to excellence. In: Williams AM, Hodges NJ, eds. Skill Acquisition in Sport: Research, Theory and Practice. London: Routledge, 2004:231-58.

22. Simon H, Chase W. Skill in chess. Am Sci 1973;61:394-403.

23. Sweller J. Cognitive load during problem solving: Effects on learning. Cognitive Sci 1988;12:257-85.

24. Paas F, Renkl A, Sweller J. Cognitive load theory and instructional design: Recent developments. Educ Psychol 2003;38:1-4.

25. Rikers R, Van Gerven P, Schmidt H. Cognitive load theory as a tool for expertise development. Instr Sci 2004;32:173-82.

26. Wulf $\mathrm{G}$, Shea $\mathrm{CH}$. Principles derived from the study of simple skills do not generalise to complex skill learning. Psychon Bull Rev 2002;9:185-211.

27. Hodges N, Franks I. Instructions, demonstrations and the learning process. In: Williams AM, Hodges NJ, eds. Skill Acquisition in Sport: Research, Theory and Practice. London: Routledge, 2004:145-74.

28. Coderre S, Mandin H, Harasym P, Fick G. The effect of diagnostic reasoning on diagnostic success. Med Educ 2003;37:695-703.

29. Rogers DA, Elstein A, Bordage G. Improving continuing medical education for surgical techniques: Applying the lessons learned in the first decade of minimal access surgery. Ann Surg 2001;233:159-66. 
30. Kahol K, Satava RM, Ferrara J, Smith ML. Effect of short-term pretrial practice on surgical proficiency in simulated environments: A randomized trial of the "preoperative warm-up" effect. J Am Coll Surg 2009;208:255-68.

31. Shirai Y, Yoshida T, Shiraishi R, et al. Prospective randomized study on the use of a computer-based endoscopic simulator for training in esophagogastroduodenoscopy. J Gastroenterol Hepatol 2008;23:1046-50.

32. Lynagh M, Burton R, Sanson-Fisher R. A systematic review of medical skills laboratory training: Where to from here? Med Educ 2007;41:879-87.

33. Sroka G, Feldman LS, Vassiliou MC, Kaneva PA, Fayez R, Fried GM. Fundamentals of laparoscopic surgery simulator training to proficiency improves laparoscopic performance in the operating room - a randomized controlled trial. Am J Surg 2010;199:15-20.

34. Hodges NJ, Franks IM. Modelling coaching practice: The role of instruction and demonstration. J Sports Sci 2002;20:793-811.

35. Raman M, Donnon T. Procedural skills education - colonoscopy as a model. Can J Gastroenterol 2008;22:767-70.

36. McLeod PJ, Steinert Y, Trudel J, Gottesman R. Seven principles for teaching procedural and technical skills. Acad Med 2001;76:1080.

37. Ringsted C. Experiential learning: Another turn on see one, do one. Med Educ 2009;43:606-7.

38. Hart S, Staveland L. Development of NASA-TLX (task load index): Results of empirical and theoretical research. In: Hancock P, Meshkati N, eds. Human Mental Workload. Amsterdam: North Holland Press, 1988:239-50. 


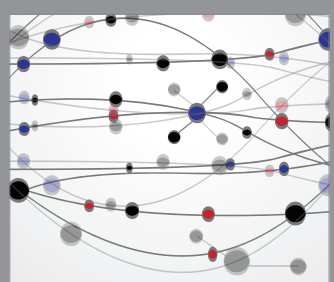

The Scientific World Journal
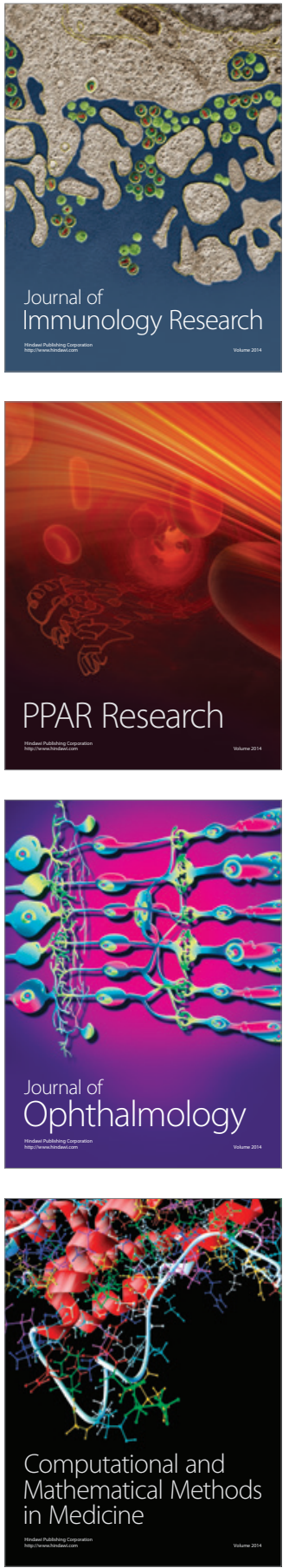

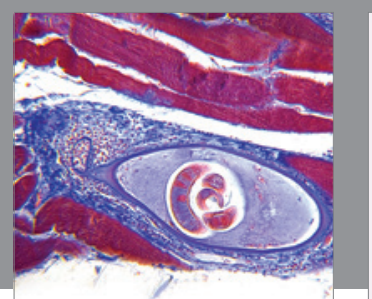

Gastroenterology Research and Practice

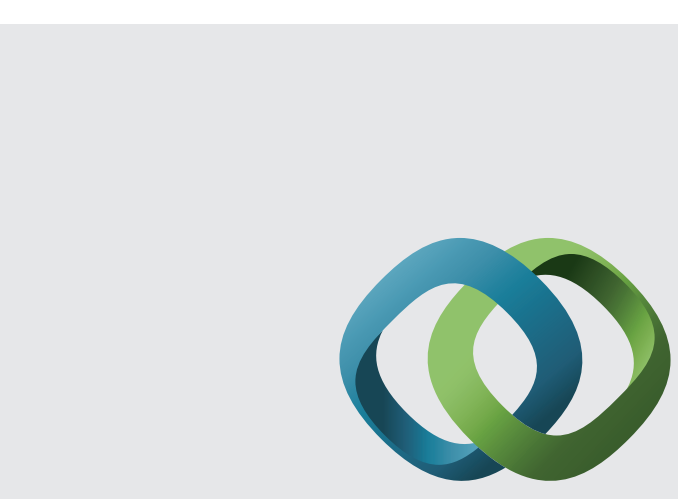

\section{Hindawi}

Submit your manuscripts at

http://www.hindawi.com
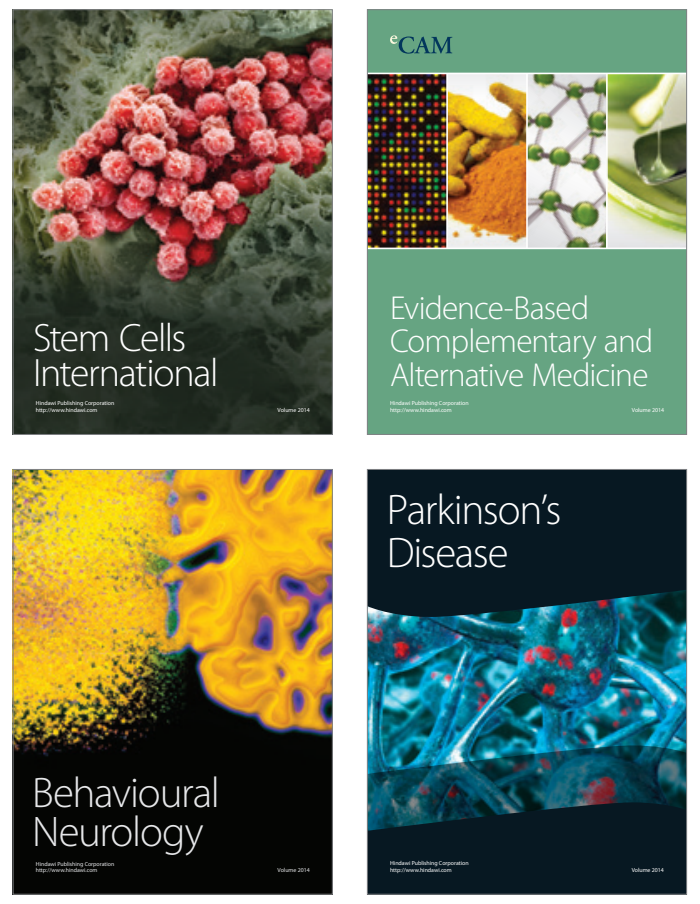
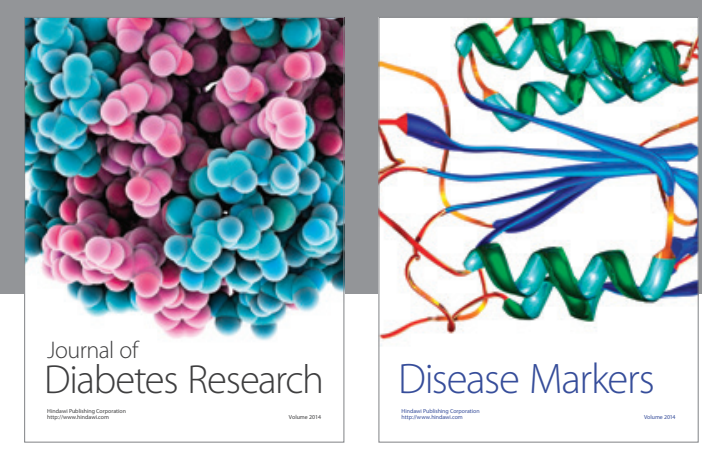

Disease Markers
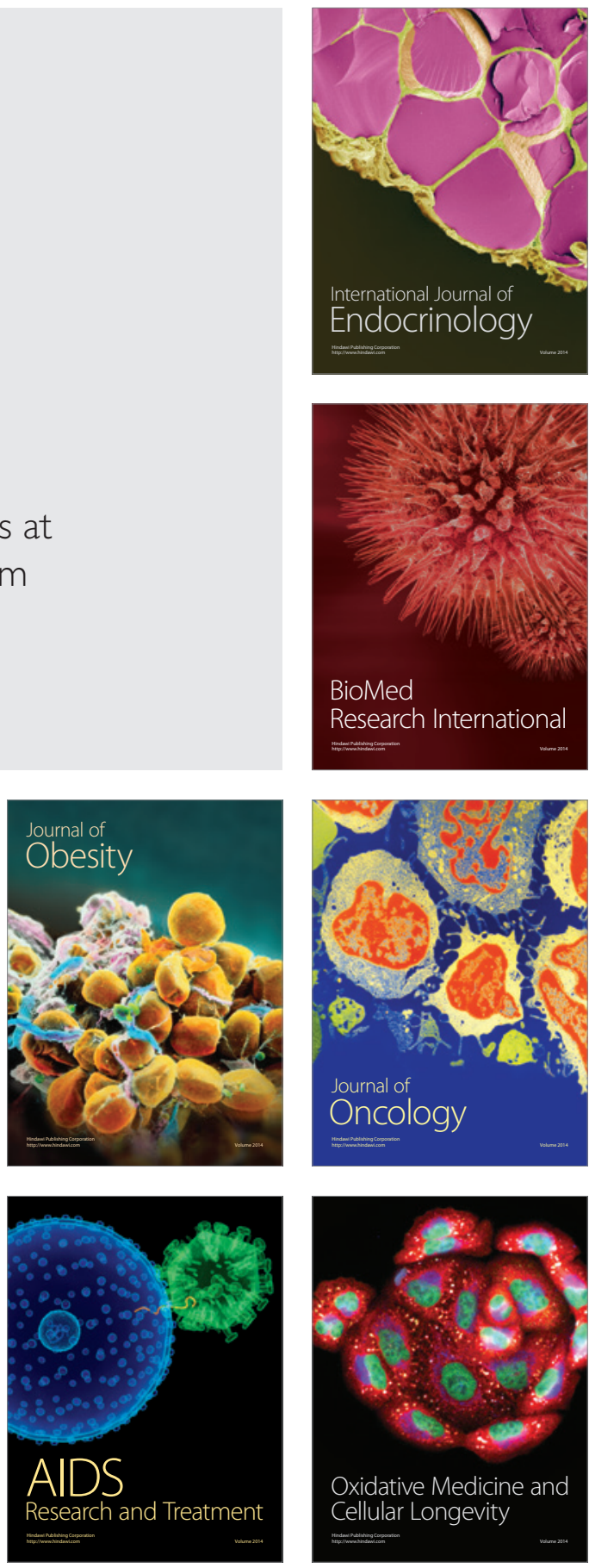